\title{
Uma história \\ de amor juvenil
}

João Maia e Pedro Prata

\section{Resumo}

Buscaremos compreender como a juventude da Candelária, uma sub-localidade da favela da Mangueira, no Rio de Janeiro, se apropria das tecnologias da comunicação e exerce expressões de uma forma de cidadania: a cultural. Esses jovens articulam alguns elementos digitais que são normalmente associados a uma racionalidade caracterizada pela velocidade moderna da produtividade objetiva, mas fazem um uso diferente nas relações de sociabilidade cotidiana e banal na comunidade. Em meio à celerada cidade contemporânea, o uso da cultura digital poderá servir de suporte para afirmar uma nova cidadania que se elabora a partir da cultura comunitária. A cultura comunitária, com sua sociabilidade popular, considera várias fontes de saber para criar e difundir o conhecimento sobre a cidade. A partir dessa sociabilidade popular e criativa, acessamos o universo de informações em fluxos acelerados. As novas articulações de poderes deslocalizam os saberes que legitimavam o conhecimento sobre a formação da sociabilidade comunitária popular.

\section{Palavras-chave}

Juventude. Comunidade.

Cidadania cultural. Mangueira.

\section{João Maia | cac_mangueira@hotmail.com}

Doutor em Sociologia pela Université De Paris V, René Descartes. Professor do Programa de Pós-Graduação em Comunicação da Universidade do Estado do Rio de Janeiro - UERJ.

Pedro Prata | cac_mangueira@hotmail.com

Mestrando do Programa de Pós-Graduação em Comunicação da Universidade do Estado do Rio de Janeiro - UERJ.

\section{Candelária: cultura omunitária popular}

Esta é uma história de amor. Um amor leve e juvenil que foi tecido à distância, através da trama das letras que sustentava uma narrativa afetuosa. A correspondência privilegiava a sedução lenta imposta pela separação dos amantes que se encontravam, em princípio, em territórios longínquos. Os enamorados só poderiam usar, no início da relação, uma ferramenta de comunicação para aproximálos. Eles se conheceram pelo Orkut. Depois, se apaixonaram pelo MSN. As conversas tela a tela se desenrolaram por mais de um mês, até 0 encontro face a face acontecer. Porém, o tempo não importava nessa história, pois os amantes estavam em permanente contato amoroso.

$\mathrm{Ane}^{1}$ nos contou que não quis marcar nada, logo de cara, por dois motivos. 0 primeiro: já estava namorando e aquele era o seu primeiro namorado. A moça estava com muitas questões, muitas dúvidas. 0 amor trazia algumas angústias e ansiedades. Esse panorama nos parece 0 retrato de toda situação jovem, que se inicia, que se elabora na novidade. 0 segundo motivo: 
o rapaz não mostrava iniciativa para que 0 encontro se realizasse.

Quando nos encontramos com Hilder ${ }^{2}$, ele explicou que sempre quis ficar com ela, mas 0 fato da moça já ter um namorado atrapalhava bastante. Mais uma vez a dúvida se instalava. Era o início de um namoro como qualquer outro, cheio de impasses, questionamentos e posicionamentos novos diante dos fatos. 0 carnaval chegou. A confusão se instalou na cidade, nas pessoas e nos corações. Assim, nessa época, a cidade ganha novas formas.

Nesse período do ano, no Rio de Janeiro, acontece um grande deslocamento das pessoas. Algumas pessoas saem para outras entrarem na cidade. E até parece que os que ficam ganham nova energia vinda do carnaval recheado de turistas. 0 cenário é de festa. A sociabilidade carioca ganha uma tonalidade especial: o sol está mais forte do que nunca, iluminando o povo que está desnudo desfilando pelas bandas de carnaval. E até pode chover que 0 povo invade as ruas assim mesmo. Nesse clima efervescente, o jovem primeiro namorado de Ane foi para uma cidade qualquer do interior e ela ficou sozinha no Rio de Janeiro. Hilder, o jovem sem iniciativa na tela do computador, também resolveu não viajar. Ganhou nova energia. Assim, logo no início do carnaval, aconteceram novos deslocamentos. Os recém enamorados de Orkut e MSN resolveram mudar o panorama e se encontrar face a face. Logo na semana seguinte, já eram namorados. Em pouco espaço de tempo descobriram várias coisas em comum e uma delas foi que as mães eram bem amigas.

Coincidência? Provavelmente. Porém, o mais estranho talvez seja exatamente 0 fato de Ane e Hilder nunca terem se visto pessoalmente antes. Os dois são moradores da Candelária, uma sub-localidade do complexo do morro da Mangueira, na cidade do Rio de Janeiro. Têm amigos e, possivelmente, até parentes em comum. Justamente por isso os seus perfis no Orkut se encontraram. Eles não lembram se foi por causa de um amigo ou por participarem de uma mesma comunidade virtual. Ela diz que fez o pedido no Orkut. Ele discorda e afirma que fez o primeiro contato. Do portal de relacionamento para o MSN foi rápido. "Eu costumava adicionar todo mundo no meu MSN. Era para tentar arrumar outro namorado mesmo." 0 namoro já tem mais de um ano e meio e os relatos são de muitos planos.

"Ainda não estamos noivos, mas queremos ter a nossa própria casa assim que terminarmos a faculdade". Ane concorda com Hilder, apesar de ambos ainda cursarem o primeiro ano do ensino médio. A história do jovem casal é um exemplo do uso dos recursos digitais na comunidade da Candelária. Além do acesso à "internet pirata", o casal incrementa o romance com músicas baixadas pela internet de forma livre e não 
pára de tirar fotos pelo celular, que garante as atualizações "imagéticas" do Orkut.

Neste artigo, buscaremos compreender como a juventude da Candelária se apropria das tecnologias da comunicação e exerce expressões de uma forma de cidadania: a cultural. Esses jovens articulam alguns elementos digitais que são normalmente associados a uma racionalidade caracterizada pela velocidade moderna da produtividade objetiva, mas fazem um uso diferente nas relações de sociabilidade cotidiana e banal na comunidade. Em meio à celerada cidade contemporânea, o uso da cultura digital poderá servir de suporte para afirmar uma nova cidadania que se elabora a partir da cultura comunitária.

No espaço compartilhado pelo homem comum e popular localizamos a experiência do que Milton Santos (2008) nomeia de "contraracionalidade". É no cotidiano construído no espaço da horizontalidade que encontramos as negociações e os jogos de forças que resistem às imposições dos processos homogeneizantes elaborados nos espaços verticais. Nesses espaços verticais, segundo Milton Santos, é onde estão presentes as empresas com suas metas de negócios mundializados, o mundo das legitimações do direito, os "macro-atores sociais" que supostamente seriam os poderosos e os gerenciamentos objetivos do tempo da produção. 0 exercício da "contra-racionalidade" resiste aos processos "globalitários" (p.2). Não falamos de resistência como um embate frontal, como luta árdua e de amargura, mas, muito pelo contrário, observamos uma cultura que se utiliza de astúcia, de sutileza e de sedução para o seu exercício no cotidiano. Cultura comunitária. Os espaços são de múltiplos usos e se entrecruzam.

A cultura comunitária com sua sociabilidade popular considera várias fontes de saber para criar e difundir o conhecimento sobre a cidade. Esta sociabilidade que exercita a "contraracionalidade" não dispensa os elementos da alta tecnologia que foram criados pelas grandes empresas que se instalam no espaço da verticalidade. A partir dessa sociabilidade popular e criativa acessamos o universo de informações em fluxos acelerados. As novas articulações de poderes deslocalizam os saberes que legitimavam o conhecimento sobre a formação da sociabilidade comunitária popular. No espaço cotidiano, na horizontalidade "contra-racional" permissiva, algumas noções consideradas no mundo acadêmico como "clássicas" deverão ser redimensionadas.

0 campo de observação deste trabalho é a comunidade da Candelária, uma das doze sublocalidades do morro da Mangueira, localizada no Rio de Janeiro. Notamos que uma certa identidade é afirmada através de uma "autorepresentação" do orgulho de ser "mangueirense" 
nas narrativas apreendidas durante a pesquisa ${ }^{3}$, porém, por outro lado, a favela da Mangueira é dividida em sub-localidades, que apresentam características próprias e especificidades entre os seus moradores. Essas diferenças são relevantes quando se estuda 0 contexto de uma sub-localidade específica.

\section{A Candelária é um lugar marcado por uma} percepção dos seus moradores baseada em um sentimento de coletividade, de pertencimento, de ancoragem e de fixidez. Mostra-se complicado para quem vive ali definir os limites geográficos: as pessoas sentem-se como "da Candelária", mas não sabem o que é o espaço delimitado dessa Candelária. Outra característica que persiste nas narrativas locais é o orgulho da grande maioria dos moradores em ser dessa comunidade. Há uma narrativa que constantemente remete ao fato daquele lugar ser o primeiro ponto de ocupação do morro, ou seja, a origem da Mangueira.

Também se fala muito da capacidade de proteção das tradições e da sucessão de valores locais de geração para geração.

Durante as entrevistas e em todo o decorrer da observação, as manifestações do sentimento de pertencimento e de fixidez daquele lugar são bastante presentes e existe uma relação de interdependência entre indivíduo e comunidade. Eles não são apenas moradores na Mangueira; além disso, são moradores da Candelária. Motivo de se ter mais orgulho ainda. Para isso, fala-se em segurança por morar ali, em construções de amizades "para sempre", em confiança entre vizinhos e em afinidades de parentesco difusas, cujas redes de primos e "agregados" parecem não ter inícios nem finais.

Ao lado desse sentimento de pertença e fixidez ao lugar, na comunidade da Candelária, é marcante a capacidade de apropriação dos novos instrumentos tecnológicos de informação e comunicação. Como um fenômeno mais recente, que se intensificou nos últimos anos, 0 uso da "tecnologia pirateada". A TV a cabo, a internet e o celular tornaram-se elementos do cotidiano e são utilizados com a criatividade e com a multiplicidade dos seus recursos. 0s moradores enviam mensagens de voz e de texto, tiram fotos que serão editadas em softwares de imagem, criam ringtones com ofunk da favela $\mathrm{e}$ transmitem os eventos da Mangueira por meio de um canal de TV comunitário. Assim, observamos não somente 0 uso simples, mas sim a releitura dessas tecnologias atrelada às demandas da cultura comunitária popular.

Para isso, o papel da juventude é muito importante. Mesmo apropriadas por pessoas diversificadas - crianças, donas-de-casa, trabalhadores, "agentes comunicacionais" ${ }^{4}, 0$ 
papel principal da reinvenção das tecnologias da informação e comunicação na comunidade da Candelária é, de fato, dos jovens.

\section{Uma juventude dilatada, estendida ou indefinida...}

0 conceito de juventude surgiu em meio às mudanças das cidades modernas no século XX. Surgiu para delimitar, mapear, cercear. Desde aquele momento, o grupo social formado por jovens é o que se encontra no período de transição entre a infância e a fase adulta. Essa é mais simples das definições sobre juventude, que a encaixa entre a primeira etapa da vida - marcada pelo desenvolvimento do corpo e pelos processos básicos de aprendizagem e de molde ao convívio social - e o período em que a pessoa se torna adulta, considerada pronta para enfrentar os desafios das atividades produtivas e de amadurecimento para as relações familiares e de reprodução. Essa seria uma definição segura e moderna.

No entanto, cada vez mais, a juventude é um fenômeno social e cultural que ultrapassa as discussões etárias. Ela engloba uma série de ações, movimentos e intervenções características da prática juvenil nos caminhos das sociedades. Para além de ser um momento de transição, a juventude é a reunião de complexidades marcantes. Ela não é passagem para nenhum outro lugar. $\mathrm{Na}$ contemporaneidade, a juventude é uma prática, cujo momento etário se retrai ou se dilata de acordo com a participação dos indivíduos e os contextos das dimensões social, cultural, política e econômica.

0 cenário desse processo de mudanças e de reconfigurações da juventude brasileira é a cidade contemporânea. Focalizamos nosso olhar no Rio de Janeiro, lugar repleto de representações e símbolos, onde é possível observar um caldeirão de contos, personagens e códigos que formam uma intensa rede de sociabilidade bem específica. A fluidez das barreiras provoca a emergência de inúmeras maneiras de mediação e interação entre os indivíduos, inclusive com jovens como agentes de mudanças e apropriações, já que 0 centro e a periferia são ambientes difusos e os seus limites encontram-se mais confusos e difusos a cada dia. Os jovens são, ao mesmo tempo, autores e protagonistas dessa construção da cidade contemporânea. Mas onde começa o centro? Até onde vai a periferia? Perguntas cada dia mais difíceis de serem respondidas no Rio. É importante ressaltar que aqui falamos no campo da cultura.

Nesse contexto, há um elemento fundamental para o processo de "trans-formações": as cidades contemporâneas se reconfiguram devido a uma cultura que denominamos comunitária popular que é criada e difundida pelo estilo de vida jovem. No Rio de Janeiro, cada vez mais, a favela ocupa nos meios de comunicação e na pesquisa acadêmica um espaço de destaque, 
de discussões e de confusões. A história da pessoa comum ganha novas dimensões quando adquire um espaço novo na produção de conhecimento popular e de mecanismos de mediação cultural. A juventude, nesse caso, também é o destaque, já que protagoniza a produção de novas estéticas e de elementos da cultura comunitária popular. Percebe-se que uma suposta barreira entre 0 "asfalto" e 0 "morro" de fato nunca existiu. Hoje, observamos que a cultura comunitária popular representa 0 conjunto da cidade. A mistura de diversas culturas se faz presente e 0 que foi rejeitado por longo tempo, por ser considerado "irrelevante" na constituição da história, hoje, ganha força para compreendermos a nossa sociabilidade das ruas. É na favela que surgem muitas tradições da cultura carioca e também onde jovens reconfiguram alguns elementos que circulam de maneira acelerada na cidade contemporânea. Essas transformações são criadas e recriadas pela juventude.

A metrópole é suporte por meio do qual se faz circular uma miríade de linguagens juvenis. Em contrapartida, ela também se inscreve nos corpos dos jovens homens e jovens mulheres, conformando 0 modo como andam, vestemse, expressam-se, amam-se e colocam-se a sonhar. Escritores da urbanidade são por ela também escritos, em uma por muitas vezes tensionada relação de intercâmbio e negociações de sentidos. Os corpos-mídia e as cidades midiáticas são reapropriações pelos meios massivos. É também por uma forte ocupação das mídias digitais que, hoje, no Brasil, veiculam-se e articulam-se inúmeras manifestações culturais juvenis (BORELLI; ROCHA, 2008, p. 29).
Na sociedade global, vemos um movimento de redefinição dos pequenos grupos sociais. Além de abrir caminhos para a formação de conjuntos de indivíduos de diferentes partes do mundo que compartilham atitudes comuns, as globalizações culturais, que se expressam através das redes de relacionamento, também têm a capacidade de interferir e até de fortalecer a construção do espaço de pequenas comunidades. Esse fortalecimento de pequenos grupos acontece justamente em ambientes onde o contato com as transformações globais é percebido mais intensamente no dia-a-dia através dos veículos de comunicação (que seja de massa, da segmentada ou da fragmentada) e da apropriação das novas tecnologias da informação. Esta possibilidade de articulação, aliada à prática de resistências diversas a possíveis processos globalitários, isto é, a "contra-racionalidade" permitindo que jovens se apropriem de elementos do cotidiano com o uso e manipulações de instrumentos tecnológicos digitais para viabilizar 0 surgimento de novas perspectivas locais.

No sistema global de trocas culturais há, de fato, processos de homogeneização em curso, de certa forma assimétricos, e há formas de vida humana que desaparecem. Nenhum desses fenômenos é particularmente novo, mas sua amplitude e velocidade, provavelmente, 0 são. № entanto, assim como formas de cultura desaparecem, outras formas são criadas - criadas localmente -, 0 que significa que elas trazem as marcas regionais que 0 cosmopolitismo festeja. 0 desaparecimento de formas culturais antigas é coerente com a manutenção de uma rica variedade de formas de vida humana apenas porque novas formas culturais, que diferem entre si, também são criadas 0 tempo todo (APPIAH, 1999, p. 221). 
Este caleidoscópio de aparecimento e desaparecimento de formas culturais, aceleradas pela globalização cultural, é um dos fatores de fortalecimento dos pequenos grupos. A partir da associação, da comunidade, os indivíduos buscam alternativas para não se diluírem, e podemos assistir isso claramente na comunidade da Mangueira.

A noção de juventude poderia caracterizar-se por representações bastante sólidas por um lado e, no sentido oposto, por outras extremamente fluidas. Teríamos a possibilidade de criar um esquema dual, o que não é a nossa intenção. A percepção do jovem está, no senso comum, relacionada a determinada faixa etária, mas, ao mesmo tempo, vinculada a um certo tipo de postura, uma forma de levar a vida, um "estado de espírito" que pode ser praticado por pessoas de qualquer idade.

Teríamos duas visões estanques sobre a questão: a primeira definiria a idade permitida para a existência de juventude e a segunda, para uma atitude que justificaria um ato juvenil (seria vândalo ou rebelde?).

Essa dualidade também está presente nas discussões acadêmicas. Desde 0 início da década de 1990, quando a questão da juventude foi resgatada às pautas tanto da Universidade quanto do Estado, a conceituação do segmento juvenil tornou-se como que desafiadora e muito problemática.

Assim, o delineamento sobre o grupo específico da juventude não é possível de ser tão fechado. Mesmo o Estado, que historicamente precisa ser regulado por definições objetivas para a sua atuação, não chegou a uma conclusão sobre quem é o indivíduo jovem. Aqui vemos um Estado confuso que talvez possa até mesmo ser caracterizado como jovem pela sua insegurança? Parece ter uma atitude jovem. Isso acontece tanto no Brasil quando em outros países que avançam nesta discussão, especialmente na Europa e na América Latina. 0 caminho mais utilizado é, sem dúvida, a definição etária, onde se estipulam as idades mínimas e máximas para o segmento juvenil. Este é um tópico importante para a formulação das políticas públicas sociais, pois envolve diretamente número de pessoas a serem atendidas e, conseqüentemente, os recursos financeiros investidos. Um trecho do livro do escritório brasileiro da UNESCO demonstra com clareza esse anseio em definir a faixa etária da juventude:

Do ponto de vista demográfico, os jovens são, principalmente, um grupo populacional que corresponde a uma determinada faixa etária que varia segundo contextos particulares, mas que, geralmente, está localizada entre os 15 e os 24 anos de idade. No caso de áreas rurais ou de pobreza extrema, 0 limite se desloca para baixo e inclui 0 grupo de 10 a 14 anos; em estratos sociais médios e altos urbanizados se amplia para cima para incluir o grupo de 25 a 29 anos. Segundo diversas circunstâncias particulares, identificam-se, como jovens, um conjunto de pessoas de idades variáveis que não pode ser tratado com começo e fim rígidos (UNESCO, 2004, p. 25).

Apesar de reconhecer a importância de se focar grupos para a execução de políticas públicas, propomos a adoção da perspectiva cultural da 
juventude. Dessa forma, retomamos a noção de que 0 segmento juvenil não é natural às sociedades, mas, sim, resultado de determinados fatos historicamente construídos. Ela está relacionada a uma prática do cotidiano e a uma postura em relação aos fenômenos culturais. Para além de diferenciar contextos sociais que supostamente determinariam a faixa etária de transição da infância para a vida adulta, interessa-nos perceber quais são as atividades e os comportamentos que constituem o "juvenil". Por meio da produção de bens simbólicos, a juventude é percebida de forma diferenciada, específica, especial. E isso não pode ser reduzido a recortes etários.

Encaradas, amiúde, como fenômenos biológicos universais, a adolescência e a juventude devem ser compreendidas, ao contrário, como artefatos de governamentabilidade, construídos e operacionalizados na intersecção de discursos políticos, acadêmicos e mercadológicos que estabelecem como aceitáveis, desejáveis ou temerárias determinadas características, configurações, associações e atitudes das populações denominadas jovens (FREIRE FILHO, 2007, p. 41).

0 caminho de encontrar as referências que norteiam as discussões sobre juventude deve também conter a perspectiva de que 0 indivíduo jovem é repleto de práticas e representações subjetivas. Isso deve ser considerado justamente para que o tema não seja encarado somente como uma "etapa, ponte, momento em consistência ou identidade reduzido a uma mera transição entre grupos de idade" (MARTÍN-BARBERO, 1998, p. 23).
A compreensão da pluralidade da noção de juventude é importante para 0 afastamento de conceitos estanques que a "racionalidade do norte" produziu, para usar o pensamento de Boaventura de Sousa Santos (2007). É importante, para não deixarmos de fora muitas experiências, pensarmos em uma "Sociologia das Ausências". Boaventura nos alerta que a "razão preguiçosa", produzida a partir de três ou quatro países do norte, jogou fora muita experiência, e, ao deixá-las de fora não nos permitiu ter uma visão ampla do presente. Assim, o que foi rejeitado pode hoje ser recuperado por uma Sociologia que respeite uma ecologia dos saberes. Os conhecimentos urbanos, populares, indígenas e tantos outros ignorados pela "ciência" podem ser levados em consideração para a compreensão do todo social.

Segundo Boaventura de Sousa Santos (2007), a racionalidade que desperdiçou experiências se manifesta de diversas formas, porém 0 autor destaca especialmente duas, a saber: a razão metonímica e a razão proléptica.

A primeira razão, a metonímica, toma a parte pelo todo e assim realiza o desperdício da experiência: contrai, diminui, subtrai o presente. "[...] Temos uma concepção do presente que é contraída, precisamente porque a concepção da racionalidade que possuímos não nos permite ter uma visão ampla do presente"(p.26).

A segunda razão indolente, a proléptica, é representada pelo progresso, pelo 
desenvolvimento do que já teríamos conquistado. É um tempo linear ideal, pois expande o futuro e o controla, de certa maneira.

0 que aqui nos interessa, agora principalmente, é trabalhar com a idéia do Boaventura (2007) quando ele combate a razão indolente com a "Sociologia das Ausências". 0 autor afirma que a racionalidade ocidental produziu a monocultura do saber e do rigor. 0 único saber rigoroso é 0 saber cientifico. Aqui, vários conhecimentos não são avaliados como importantes e dessa maneira cometem 0 "epistemicídio", que seria a morte dos conhecimentos alternativos. "A primeira forma de produção de inexistência, de ausência, é a ignorância"(p.29). Hoje, não mais podemos ignorar as diversas formas de usos da cultura que os jovens que vivem nas cidades fazem para criar uma cultura comunitária popular.

Os grupos são intensamente variados, inclusive aqueles organizados em movimentos sociais. Há os jovens estudantes, único coletivo organizado que era reconhecido até os anos setenta; a juventude das periferias das grandes metrópoles, que se articula em torno de símbolos-resultados de posições políticas e expressões culturais, como o hip hop; os jovens rurais, que têm 0 seu contingente populacional reduzido por conta dos processos de urbanização, mas que resgatam a sua relevância em discussões como a do protecionismo dos países ricos; as mulheres jovens, que renovam o feminismo e ainda são o centro dos debates sobre direitos sexuais e reprodutivos; os jovens com múltiplas identidades étnicas, que nos remetem a uma infinidade de questões - negros, latinos, afro-latinos, afrocaribenhos, árabes, orientais, leste-europeus; os jovens com deficiência, que sofrem um ciclo de invisibilidade apesar de pesquisas demográficas comprovarem que são mais de 15\% dos jovens no mundo (WERNECK, 2005, p. 16); a juventude com todas as orientações sexuais e também identidades de gênero, que invadem as avenidas nas paradas gays e ganham espaço para expressarem suas afetividades; os jovens de comunidades indígenas, quilombolas e tradicionais, que, cada vez mais, simbolizam o elo local/global; e a juventude que renova os movimentos sociais e consolida a influência política das organizações não-governamentais, através de reivindicações que transitam entre o coletivo e os interesses públicos difusos, como direitos humanos, acesso à educação de qualidade, garantia de condições saudáveis de trabalho e produção e, com grande e recente destaque, a preservação do meio ambiente.

A noção de estilo de vida, apresentada por Anthony Giddens (2002), é fundamental para a pensarmos sobre a questão da juventude. Para 0 autor, 0 estilo de vida está, necessariamente, em contraponto com a tradição e alinhada com a modernidade. Isso acontece porque, enquanto a tradição se pauta por ordenações relativamente fixas, a modernidade possibilita ao indivíduo uma gama maior de escolhas, ao mesmo tempo em que fornece pouca ajuda sobre as opções que devem 
ser selecionadas. Nesse contexto, ele diz que "um estilo de vida pode ser definido como um conjunto mais ou menos integrado de práticas que um indivíduo abraça, não só porque essas práticas preenchem necessidades utilitárias, mas porque dão forma material a uma narrativa particular da auto-identidade" (p.79).

Dessa forma, a juventude se coloca muito mais como um grupo que se "encontra" nesse estilo de vida do que por coincidências etárias. As práticas do cotidiano, as rotinas que vão incorporando as maneiras de vestir, os modos e maneiras de agir, de comer e os lugares que freqüentamos estariam, segundo o autor, reflexivamente abertas à mudança da auto-identidade.

Massimo Canevacci. (2005) trabalha justamente com a noção de juventude, mas afirma a existência da dilatação da noção de jovem, "virando do avesso às categorias que fixavam faixas etárias definidas e claras passagens geracionais". Desta forma, os jovens são intermináveis:

Cada jovem, ou melhor, cada ser humano, cada indivíduo pode perceber sua própria condição de jovem como não-terminada e inclusive como não-terminável. Por isso, assiste-se a um conjunto de atitudes que caracterizam de modo absolutamente único nossa era: as dilatações juvenis. 0 dilatar-se da autopercepção enquanto jovem sem limites de idade definidos e objetivos define as barreiras tradicionais, tanto sociológicas e biológicas. Morrem as faixas etárias, morre 0 trabalho, morre o corpo natural, desmorona a demografia, multiplicam-se as identidades móveis e nômades. E nasce a antropologia da juventude (p.29).
Ao articularmos os conceitos de estilo de vida e juventude dilatada, percebemos a congruência de elementos culturais que permeiam jovens da comunidade da Candelária. Ao invés de um contingente etário, a juventude se apresenta como um grupo de indivíduos com formas plurais de sociabilidades e práticas culturais. Ao revelar as suas próprias noções de juventude - através das narrativas e das ações do cotidiano - os jovens da comunidade também não se atêm a limites etários, mas sim a um conjunto de atividades e representações subjetivas e sutis que moldam 0 segmento juvenil. Na adoção de perspectivas culturais para discorrer sobre a juventude, buscamos reafirmar a importância da produção de conhecimento dos indivíduos moradores da favela.

\section{Cidadania cultural e jovens na Candelária}

Historicamente aplicada à ordem e à regulamentação, a noção de cidadania, principalmente associada à noção de juventude, ganha contornos múltiplos na contemporaneidade. Vamos fazer uma breve panorâmica sobre 0 assunto. A origem do conceito está diretamente ligada à formação dos Estados modernos europeus a partir do impacto causado pelo capitalismo e as revoluções industriais. 0 delineamento de conglomerados de trabalhadores possibilitou o surgimento da coletividade, da identidade de classe, justamente em contraposição ao grupo minoritário detentor 
de maiores recursos econômicos (LUCA, 2003, p. 469). A noção de cidadania permeou o século XIX e a primeira metade do século XX pautada pelas grandes instituições. Ela chegou a ser apropriada como recurso de diferenciação: 0 cidadão era o indivíduo branco, rico, macho.

A partir da II Guerra Mundial e com a ascensão de movimentos políticos mais organizados, a cidadania ficou intimamente atrelada à intervenção política de espaços institucionalizados. Qualquer um poderia exercer sua cidadania, desde que reconhecesse o coletivo como instrumento para a conquista de sua demanda ou seu direito. A obra clássica de Theodore Marshall (1967) - "Cidadania, classe social e status" -, pela primeira vez, organiza - em uma perspectiva típica da modernidade -0 conceito de cidadania. A tese principal do autor é que a cidadania é 0 exercício social de ter e de aplicar direitos, que, ao longo dos séculos, absorveu novas frentes. Os direitos civis surgiram no século XVIII, em torno das questões de liberdade individual, fé, justiça e garantia à propriedade. Os direitos políticos, oriundos do século XIX, eram baseados na possibilidade dos cidadãos em interferir no poder político, como, por exemplo, por meio do voto e do parlamento. Consolidados no século XX, os direitos sociais defendiam que todo cidadão precisa de condições justas de exercer a sua vida em sociedade, sobre 0 tripé educação-saúdetrabalho (MESQUITA, 2005, p. 32).
Entretanto, observamos outras formas de exercício da cidadania na contemporaneidade. Mais especificamente - e como desdobramento desta pesquisa -, a cidadania de jovens da Candelária que não se alinham à ordem, à "racionalidade do norte", como diria Boaventura de Sousa Santos (2007), ou às regulamentações do Estado juvenil. Miguel Darcy de Oliveira e Rajesh Tandon contextualizam esse deslocamento:

0 movimento atual, maciço e quase universal, no sentido de maior participação e influência dos cidadãos, é um fenômeno novo. Não está sendo promovido por uma estrutura universal. Não possui endereço fixo. Não busca convertidos nem militantes políticos. Seu alvo não é 0 poder do Estado. Em seu centro está a figura do cidadão (1995, p. 12).

Quando um morador da Candelária compra uma música em arquivo MP3 por cinqüenta centavos, percebemos que a fala está muito mais vinculada à noção de direitos, ao acesso, do que ao simples descumprimento dos termos legais de compra ou de autoria. Isto também acontece quando uma criança adota o hobby de colecionar cartões de crédito espalhados, jogados no chão, pelos becos da favela - "provavelmente" (não podemos afirmar) oriundos de pequenos furtos.

São elaboradas diversas apropriações culturais de produtos que na "racionalidade vertical" teriam um objetivo a cumprir e que na "racionalidade da comunidade" são re-significados.

Assim como em outros processos sociais, a produção de conhecimento ainda tem atores 
centrais e periféricos? Não, não podemos mais ver centros e bordas nesse processo que nos leva a pensar numa Sociologia das Ausências, que valoriza 0 que esteve de fora nas interpretações das cidades. Preferimos pensar em "agentes comunicacionais". São os homens comuns, da comunidade, que fazem cotidianamente as re-significações dos produtos culturais. É uma pessoa importante como o Jeferson ${ }^{5}$, 0 jovem que é referendado na Candelária como o hacker comunitário que faz circular idéias difusas, referências de diversas ordens, códigos e imagens sempre renovadas que fazem as bordas se diluírem. Ele coordena a primeira e mais importante lan house da localidade e distribui internet banda larga a preços mais acessíveis para cento e vinte casas. E ressalta: "não quero ampliar a clientela. Este tamanho está muito bom. Se aumentar, perde a qualidade". Na sua fala, percebemos uma série de questões relevantes para problematizarmos a dimensão da cultura comunitária que se expande através dos jovens na cidade contemporânea. Em primeiro lugar, a sua atuação começou justamente como "beneficiário" de um projeto social de uma grande organização não-governamental: o CDI - Comitê pela Democratização da Informática ${ }^{6}$. Apesar de ser a liderança dos serviços de "pirataria tecnológica", Jeferson conheceu a informática por meio de uma $0 \mathrm{NG}$ vinculada a normas verticais - na perspectiva de Milton Santos -, cuja grande financiadora é a norteamericana Microsoft. Após aprender várias técnicas de softwares e hardwares, ele montou um "telecentro" comunitário e uma lan house. Apesar de ambas terem acesso à "internet pirateada", cada uma tem uma função diferente: "o telecentro é para o pessoal da comunidade acessar a internet, principalmente quem não tem em casa. A lan house é para ficar jogando, baixando arquivo e o que quiserem". Outro ponto é a despreocupação com a concorrência: "já há um outro fornecedor de internet lá no alto. Não me preocupo não. É mais gente com internet." E, por fim, ele revela que, "apesar de acharem estranho", ele trabalha completamente dentro da legislação brasileira: "aqui no Brasil, não existe nenhuma lei que proíba a distribuição de conexão banda larga. Nos Estados Unidos, sim. Mas, aqui, eu posso tranquilamente distribuir para quem quiser." A permissividade é um dado constante na elaboração da cultura comunitária popular pela qual o jovem transita e se reapropria.

Entre todas essas declarações e também entre linhas, idas, vindas e interrupções dentro da lan house, é importante destacar que a preocupação central de Jeferson é 0 acesso ao conhecimento e o direito à produção de conteúdo por moradores da favela. Ele defende o uso de ferramentas 
de chat e comunidades virtuais como forma de "crescimento pessoal" e acha que quanto mais informação circular, melhor. Ele coloca a favela no mundo e o mundo penetra na favela. Jeferson realiza uma forma de Sociologia das Ausências quando nada escapa ao seu fazer circular de informações.

A história do casal Ane e Hilder também revela formas inovadoras de apropriação das tecnologias da comunicação. Ele trabalha na videolocadora, que, na verdade, é um espaço com muito mais serviços do que aluguel de filmes. Aqui, todos os espaços são reinventados. Nada tem apenas um único uso. As casas estão em permanente construção, em obras. É por isso, talvez, que vemos as casas sem reboco, sem a pintura de acabamento. Nada está pronto e acabado. Em primeiro lugar, a grande maioria dos DVDs são "pirateados". Há uma preocupação especial com aqueles de conteúdo pornográfico, que não ficam expostos na prateleira, "por causa das crianças". Mas quando apontamos para o cartaz do DVD pornô do Alexandre Frota, Hilder somente ri. Ele conta também que grande parte da renda da loja são os milhares de sons, imagens e vídeos baixados da internet, que podem ser comprados tanto para montagem de acervo musical - na atual tendência de substituição dos CDs - quanto para personalizar os celulares. Mas, a grande novidade é 0 software que triplica 0 volume dos sons dos aparelhos mobiles. (Será o tema para um próximo artigo, né?) Ou seja, é possível entrar na lan house com um celular comum e sair com um dispositivo repleto de música para ser usado inclusive em pequenas festas. Também usuária e produtora dos "recursos piratas", Ane faz questão de ressaltar as vantagens amorosas. "Ele sempre manda fotos ou músicas românticas. Eu adoro!" Com essas histórias miúdas, cotidianas e banais percebemos a emergência do jovem cidadão que se articula por meio de práticas culturais. Esse jovem faz reapropriações dos produtos da acelerada cultura contemporânea. A noção de direito é conquistada por meio de ações matreiras, astutas, amorosas e sedutoras típicas do cotidiano, que moldam o exercício de uma cidadania que consideramos cultural.

\section{Referências Bibliográficas}

APPIAH, Kwane Anthony. Cultura, comunidade e cidadania. In: HELLER, Agnes. A crise dos paradigmas em ciências sociais e os desafios para o século XXI. Rio de Janeiro: Contraponto, 1999.

BORELLI, Silvia Helena Simões; ROCHA, Rose de Melo. Juventudes, midiatizações e nomadismos: a cidade como arena. Comunicação, Mídia e Consumo. São Paulo, v. 5 n. 13, p. 27-40, jul. 2008.

CANEVACCI, Massimo. Culturas eXtremas: mutações juvenis nos corpos das metrópoles. Tradução: Alba Olmi. Rio de Janeiro: DP\&A, 2005.

CUBIDES, H., J., TOSCANO, M. C. \& VALDERRAMA, C. E. H. (orgs.). Viviendo a toda: jóvenes, territorios cultuales y nuevas sensibilidades. Bogotá: Siglo Del Hombre/DIUC, 1998.

FREIRE FILHO, João. Reinvenções da resistência juvenil: os estudos culturais e as micropolíticas do cotidiano. Rio de Janeiro: Mauad X, 2007. 
GIDDENS, Anthony. A terceira via: reflexões sobre o impasse político atual e o futuro da social-democracia. 4. ed. Rio de Janeiro: Record, 2002.

LUCA, Tânia Regina de. Direitos Sociais no Brasil. In: PINSKY, Jaime; PINSKY, Carla Bassanezi (orgs). História da cidadania. São Paulo: Contexto, 2003.

MAFFESOLI, Michel. 0 tempo das tribos: 0 declínio do individualismo nas sociedades de massa. Rio de Janeiro: Forense Universitária, 1987.

MAIA, João. Os agentes comunicacionais da Mangueira: fluxos e movimentos culturais. In: COG0, Denise; MAIA, João (org.). Comunicação para a cidadania. Rio de Janeiro: EDUerj, 2006.

MARSHALL, Theodore. Cidadania, classe social e status. Rio de Janeiro: Zahar, 1967.

MARTIN-BARBER0, Jesus. Jóvenes: desordem cultural y palimpsestos de identidad. In: CUBIDES, Humberto, TOSCANO, Maria \& VALDERRAMA, Carlos (orgs.). Viviendo a toda: jóvenes, territorios cultuales y nuevas sensibilidades. Bogotá: Siglo Del Hombre/DIUC, 1998. p. 22-37.

MESQUITA, Adriana de Andrade. Com licença, eu vou à luta: 0 desafio de inserção das mulheres da periferia carioca no mercado de trabalho. 2005. Dissertação (Mestrado em Política Social)Faculdade de Serviço Social, Universidade Federal Fluminense, 2005.

OLIVEIRA, Miguel Darcy de; TANDON, Rajesh. A emergência de uma sociedade global. In: Cidadãos: construindo a sociedade civel planetária. Relatório da Civicus. [S.I.]: Prol, 1995. SANTOS, Milton. A natureza do espaço: técnica e tempo, razão e emoção. São Paulo: Universidade de São Paulo, 2002.
SANTOS, Milton. Por uma outra globalização: do pensamento crítico à consciência universal. 15. ed. Rio de Janeiro: Record, 2008.

SOUSA SANTOS, Boaventura de . Renovar a teoria crítica e reinventar a emancipação social. São Paulo: Boitempo, 2007.

UNESCO. Políticas públicas de/para/com juventudes. Brasília, 2004.

WERNECK, Claudia. Manual sobre desenvolvimento inclusivo para mídia e profissionais de comunicação. Rio de Janeiro: WVA, 2005. 


\begin{tabular}{|c|c|}
\hline A story of young love & Una historia de amor juvenil \\
\hline $\begin{array}{l}\text { Abstract } \\
\text { The main objective of this article is to understand } \\
\text { how young people from Candelária, a sub-locality } \\
\text { in favela Mangueira, in Rio de Janeiro, appropriate } \\
\text { communication technologies to carry out expressions } \\
\text { of a specific kind of citizenship: the cultural one. } \\
\text { These young people articulate digital elements } \\
\text { that are normally associated to a rationality that is } \\
\text { characterized by the modern velocity of the objective } \\
\text { productivity, but they also make a different use in } \\
\text { those relations of quotidian and banal sociability } \\
\text { in their community. In the contemporary fast- } \\
\text { changing cities, digital culture can be a support to } \\
\text { affirm a new citizenship that is elaborated inside } \\
\text { communitarian culture. Communitarian culture, } \\
\text { with its popular sociability, considers several } \\
\text { sources of information to create and mobilize } \\
\text { knowledge about the city. From this popular and } \\
\text { creative sociability, we have access to a universe of } \\
\text { information in accelerated flows. The new powering } \\
\text { articulations 'unlocate' the learning that used to } \\
\text { legitimize the knowledge on the formation of the } \\
\text { popular communitarian sociability. } \\
\text { Keywords } \\
\text { Communitarian sociability. Cultural citizenship. } \\
\text { Favela Mangueira. }\end{array}$ & $\begin{array}{l}\text { Resumen } \\
\text { Buscaremos comprender como la juventud de } \\
\text { la Candelária, una sub-localidad de la favela de } \\
\text { Mangueira, en Rio de Janeiro, se apropia de las } \\
\text { tecnologías de la comunicación y ejerce expresiones } \\
\text { de una forma de ciudadanía: la cultural. Estos } \\
\text { jóvenes articulan algunos elementos digitales que } \\
\text { son normalmente asociados a una racionalidad } \\
\text { caracterizada por la velocidad moderna de la } \\
\text { productividad objetiva, pero hacen un uso diferente } \\
\text { en las relaciones de sociabilidad cotidiana y banal } \\
\text { en la comunidad. En medio de la acelerada ciudad } \\
\text { contemporánea, el uso de la cultura digital podrá } \\
\text { servir de soporte para afirmar una nueva ciudadanía } \\
\text { que se elabora a partir de la cultura comunitaria. } \\
\text { La cultura comunitaria, con su sociabilidad popular, } \\
\text { considera varias fuentes de saber para crear y } \\
\text { difundir el conocimiento sobre la ciudad. A partir } \\
\text { de esa sociabilidad popular y creativa accedemos al } \\
\text { universo de la información en flujos acelerados. Las } \\
\text { nuevas articulaciones de poderes deslocalizan los } \\
\text { saberes que legitimaban el conocimiento sobre la } \\
\text { formación de la sociabilidad comunitaria popular. } \\
\text { Palabras clave } \\
\text { Juventud. Comunidad. Ciudadanía cultural. } \\
\text { Mangueira. }\end{array}$ \\
\hline
\end{tabular}




\section{Expediente}

A revista E-Compós é a publicação científica em formato eletrônico da Associação Nacional dos Programas de Pós-Graduação em Comunicação (Compós). Lançada em 2004, tem como principal finalidade difundir a produção acadêmica de pesquisadores da área de Comunicação, inseridos em instituições do Brasil e do exterior.
E-COMPÓS I www.e-compos.org.br I E-ISSN 1808-2599

Revista da Associação Nacional dos Programas de Pós-Graduação em Comunicação. Brasília, v.11, n.1, jan./abr. 2008.

A identificação das edições, a partir de 2008, passa a ser volume anual com três números.

\section{CONSELHO EDITORIAL}

\section{Afonso Albuquerque}

Universidade Federal Fluminense, Brasil

Alberto Carlos Augusto Klein

Universidade Estadual de Londrina, Brasi

Alex Fernando Teixeira Primo

Universidade Federal do Rio Grande do Sul, Brasi

Alfredo Vizeu

Universidade Federal de Pernambuco, Brasil

Ana Carolina Damboriarena Escosteguy

Pontifícia Universidade Católica do Rio Grande do Sul, Brasil

Ana Silvia Lopes Davi Médola

Universidade Estadual Paulista, Brasil

André Luiz Martins Lemos

Universidade Federal da Bahia, Brasil

Ângela Freire Prysthon

Universidade Federal de Pernambuco, Brasil

Antônio Fausto Neto

Universidade do Vale do Rio dos Sinos, Brasil

Antonio Carlos Hohlfeldt

Pontifícia Universidade Católica do Rio Grande do Sul, Brasil

Arlindo Ribeiro Machado

Universidade de São Paulo, Brasil

César Geraldo Guimarães

Universidade Federal de Minas Gerais, Brasi

Cristiane Freitas Gutfreind

Pontifícia Universidade Católica do Rio Grande do Sul, Brasil

Denilson Lopes

Universidade Federal do Rio de Janeiro, Brasil

Eduardo Peñuela Cañizal

Universidade Paulista, Brasil

Erick Felinto de Oliveira

Universidade do Estado do Rio de Janeiro, Brasil

Francisco Menezes Martins

Universidade Tuiuti do Paraná, Brasil

Gelson Santana

Universidade Anhembi/Morumbi, Brasil

Hector Ospina

Universidad de Manizales, Colômbia

leda Tucherman

Universidade Federal do Rio de Janeiro, Brasil

Itania Maria Mota Gomes

Universidade Federal da Bahia, Brasil

Janice Caiafa

Universidade Federal do Rio de Janeiro, Brasil

Jeder Silveira Janotti Junior

Universidade Federal da Bahia, Brasil
John DH Downing

University of Texas at Austin, Estados Unidos

José Luiz Aidar Prado

Pontifícia Universidade Católica de São Paulo, Brasil

José Luiz Warren Jardim Gomes Braga

Universidade do Vale do Rio dos Sinos, Brasi

Juremir Machado da Silva

Pontifícia Universidade Católica do Rio Grande do Sul, Brasil

Lorraine Leu

University of Bristol, Grã-Bretanha

Luiz Claudio Martino

Universidade de Brasília, Brasil

Maria Immacolata Vassallo de Lopes

Universidade de São Paulo, Brasil

Maria Lucia Santaella

Pontifícia Universidade Católica de São Paulo, Brasil

Mauro Pereira Porto

Tulane University, Estados Unidos

Muniz Sodre de Araujo Cabral

Universidade Federal do Rio de Janeiro, Brasil

Nilda Aparecida Jacks

Universidade Federal do Rio Grande do Sul, Brasil

Paulo Roberto Gibaldi Vaz

Universidade Federal do Rio de Janeiro, Brasil

Renato Cordeiro Gomes

Pontifícia Universidade Católica do Rio de Janeiro, Brasil

Ronaldo George Helal

Universidade do Estado do Rio de Janeiro, Brasil

Rosana de Lima Soares

Universidade de São Paulo, Brasil

Rossana Reguillo

Instituto Tecnológico y de Estudios Superiores do Occidente, México

Rousiley Celi Moreira Maia

Universidade Federal de Minas Gerais, Brasil

Sebastião Carlos de Morais Squirra

Universidade Metodista de São Paulo, Brasil

Simone Maria Andrade Pereira de Sá

Universidade Federal Fluminense, Brasil

Suzete Venturelli

Universidade de Brasília, Brasil

Valério Cruz Brittos

Universidade do Vale do Rio dos Sinos, Brasil

Veneza Mayora Ronsini

Universidade Federal de Santa Maria, Brasil

Vera Regina Veiga França

Universidade Federal de Minas Gerais, Brasil

\section{COMISSÃO EDITORIAL}

Ana Gruszynski I Universidade Federal do Rio Grande do Sul, Brasil João Freire Filho I Universidade Federal do Rio de Janeiro, Brasil Rose Melo Rocha I Escola Superior de Propaganda e Marketing, Brasil

\section{CONSULTORES AD HOC}

Bianca Freire-Medeiros I Fundação Getulio Vargas, Brasil Josimey Costa da Silva I Universidade Federal do Rio Grande do Norte, Brasil Maria Conceição Golobovante I Pontifícia Universidade Católica de São Paulo, Brasil Marlyvan Moraes de Alencar I Centro Universitário SENAC-SP, Brasil Miriam de Souza Rossini I Universidade Federal do Rio Grande do Sul, Brasil Paulo Ribeiro I Pontifícia Universidade Católica do Rio de Janeiro, Brasil Rita Alves de Oliveira I Centro Universitário SENAC, Brasil

REVISÃO DE TEXTO E TRADUÇÃO I Everton Cardoso ASSISTÊNCIA EDITORIAL E EDITORAÇÃO ELETRÔNICA I Raquel Castedo
COMPóS I www.compos.org.br

Associação Nacional dos Programas de Pós-Graduação em Comunicação

Presidente

Erick Felinto de Oliveira

Universidade do Estado do Rio de Janeiro, Brasil erickfelinto@uol.com.br

Vice-presidente

Ana Silvia Lopes Davi Médola

Universidade Estadual Paulista, Brasil

asilvia@faac.unesp.br

Secretária-Geral

Denize Correa Araújo

Universidade Tuiuti do Paraná, Brasil

denizearaujo@hotmail.com 